\title{
Coronary stent disease: When will enough be enough?
}

Igor E. Konstantinov, MD, PhD, Pankaj Saxena, MCh, DNB, and Jaffar Shehatha, FRCS, FRACS, Perth, Australia

Drug-eluting stents significantly modify and often complicate the natural history of coronary artery disease. This report emphasizes that every patient with multivessel coronary artery disease must be reviewed by a surgeon and properly informed before stenting.

\section{CLINICAL SUMMARY}

A 60-year-old man was transferred to the Sir Charles Gairdner Hospital with unstable angina. His comorbidities were obesity (body mass index $33.6 \mathrm{~kg} / \mathrm{m}^{2}$ ), hypertension, type II diabetes mellitus requiring insulin, hypercholesterolemia, and chronic renal failure (creatinine $150 \mathrm{mmol} / \mathrm{L}$ ) due to diabetic nephropathy. The patient was an ex-smoker. Left ventricular ejection fraction was $45 \%$ with hypokinesis of the inferolateral wall. He had severely diseased left anterior descending (LAD) and left circumflex (LCx) coronary arteries with multiple in-stent stenoses (Figure 1) and a small nondominant right coronary artery.

The patient had been previously managed elsewhere. In March of 2002, he was admitted with unstable angina and underwent percutaneous transluminal coronary angioplasty (PTCA) of the obtuse marginal (OM) branch. During angioplasty, the OM branch was dissected. A 2.5-mm Tsunami stent (Terumo Corporation, Tokyo, Japan) and a 2.5-mm Pixel stent (Guidant, Santa Clara, Calif) were placed to overlap the area of dissection. In October of 2002, unstable angina and in-stent stenosis of the OM developed, which were managed by PTCA alone. In May of 2003, unstable angina recurred. The patient underwent repeat PTCA to the LAD and LCx arteries, during which 3 Cypher stents (Cordis Corporation, Warren, NJ) were placed in the proximal LAD occluding the second diagonal branch and 4 Zeta stents (Abbott Laboratories, Abbott Park, Ill) were placed in the LCx. In January of 2007, the patient presented with unstable angina, inferolateral myocardial infarction, and pulmonary edema. The in-stent stenosis in the distal LCx was demonstrated, and the flow was restored with 4 Cypher stents. In March of 2007, he presented again with a prolonged episode of angina and inferolateral infarction and was found to have

From the Department of Cardiothoracic Surgery, Sir Charles Gairdner Hospital, University of Western Australia, Perth, Australia.

Received for publication March 31, 2008; accepted for publication April 13, 2008.

Address for reprints: Igor E. Konstantinov, MD, PhD, Associate Professor of Surgery,

University of Western Australia, Sir Charles Gairdner Hospital, Nedlands, Perth,

WA 6009, Australia (E-mail: konstantinov.igor@alumni.mayo.edu).

J Thorac Cardiovasc Surg 2009;137:1020-1

$0022-5223 / \$ 36.00$

Copyright (C) 2009 by The American Association for Thoracic Surgery doi:10.1016/j.jtcvs.2008.04.005
$70 \%$ in-stent stenosis of the LAD. The patient underwent repeat PTCA with 2 Cypher stents placed in the LAD and distal LCx. Unstable angina recurred in 1 week. The patient was transferred to the Sir Charles Gairdner Hospital and seen by a cardiothoracic surgeon for the first time.

On admission, the patient continued to have unstable angina at rest despite receiving aspirin, clopidogrel, and heparin infusion. An intraaortic balloon pump was inserted. Levosimendan infusion was started, and the patient underwent urgent coronary artery bypass surgery with a standard cardiopulmonary bypass. The left internal thoracic artery was anastomosed to the LAD. A sequential saphenous vein graft was anastomosed to the first and second diagonal branches. An individual saphenous vein graft was anastomosed to the OM. The terminal branch was completely obliterated and not graftable. At 3 month of follow-up, the patient was doing well and free of angina.

\section{DISCUSSION}

During a 5-year period, the patient received 15 stents and 6 coronary angiograms, was admitted to the hospital 7 times with unstable angina, and had 2 myocardial infarctions that resulted in a significant decrease in left ventricular function. The patient apparently did not want surgery. Yet, the fact is that the patient was not given an opportunity to see a cardiothoracic surgeon. Could any patient be properly informed about surgery without seeing a surgeon? It is likely that most patients undergoing coronary angioplasty are not properly informed of the risk and benefits of surgery. ${ }^{1-3}$

At present, for patients with multivessel disease, coronary artery bypass grafting is associated with lower mortality and lower rates of myocardial infarction and repeat revascularization. ${ }^{4,5}$ Currently, the real controversy is not whether surgery or stenting should be performed in a diabetic patient with multivessel coronary artery disease, but rather why patients with symptoms and anatomy known to benefit from surgery are still subjected to percutaneous coronary interventions. ${ }^{2,3}$ To properly describe this iatrogenic course of coronary artery disease, we coined the term "coronary stent disease." It seems that coronary stent disease may affect both patients and cardiologists. Both may require urgent surgical intervention.

\section{CONCLUSIONS}

We believe that every patient with multivessel coronary artery disease must be treated by a multidisciplinary team that includes a cardiothoracic surgeon. This must become a standard of care. Primum non nocere! 

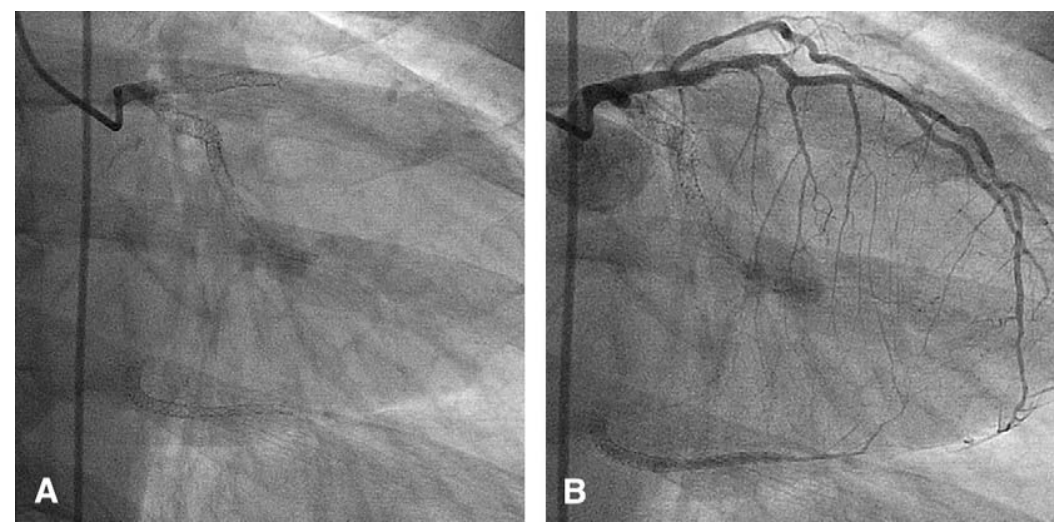

FIGURE 1. Multiple stents in the LAD, OM, and terminal branches of the LCx coronary artery (A), with significant in-stent stenosis in the LAD and complete in-stent occlusion of the OM and terminal branches (B).

\section{References}

1. Califf RM. Stenting or surgery: an opportunity to do it right. $J$ Am Coll Cardiol. 2005;46:589-91.

2. Opie LH, Commerford PJ, Gersh BJ. Controversies in stable coronary artery disease. Lancet. 2006;367:69-78.

3. Taggart DP. Coronary artery bypass grafting is still the best treatment for multivessel and left main disease, but patients need to know. Ann Thorac Surg. 2006;82:1966-75.
4. Hannan EL, Wu C, Walford G, Culliford AT, Gold JP, Smith CR, et al. Drugeluting stents versus coronary-artery bypass grafting in multivessel coronary artery disease. $N$ Engl J Med. 2008;358:331-41.

5. Farkouh ME, Dangas G, Leon MB, Smith C, Nesto R, Buse JB, et al. Design of the Future Revascularization Evaluation in patients with diabetes mellitus: optimal management of multivessel disease (FREEDOM) trial. Am Heart J. 2008;155: $215-23$.

\title{
Pneumothorax in two siblings: Is there a genetic basis for recurrence?
}

\author{
John Henderson, BMBS, ${ }^{\text {a }}$ Pradeep Narayan, FRCS, ${ }^{\text {a }}$ Sarah F. Smithson, FRCP, ${ }^{\mathrm{b}}$ and Anthony Morgan, FRCS, ${ }^{\mathrm{a}}$ \\ Bristol, United Kingdom
}

The incidence of primary pneumothorax is reported as 18 to 28 per 100,000 per year for men and 1.2 to 6 per 100,000 per year for women, with approximately $10 \%$ having a positive family history. ${ }^{1}$ Although recurrent pneumothoraces on the ipsilateral side is seen in less than $5 \%$ of cases and may be dependent on the surgical technique, contralateral recurrence may arise because of individual or familial predisposition. Autosomal dominant inheritance of recurrent pneumothorax within families has been associated with the mutation of the folliculin (FLCN) gene. ${ }^{2}$ Patients who have blebs, bullae, and recurrent pneumothorax with or without a family history may have mutations in this gene. ${ }^{3}$ We describe 2 siblings who had multiple ipsilateral and con-

\footnotetext{
From the Department of Thoracic Surgery, ${ }^{\text {a }}$ Bristol Royal Infirmary, Department of Clinical Genetics, ${ }^{\text {b }}$ St Michaels Hospital, Bristol, United Kingdom. Received for publication Feb 15, 2008; accepted for publication March 18, 2008. Address for reprints: Anthony Morgan, FRCS, Bristol Royal Infirmary Bristol UK, Thoracic Surgery, Marlborough Street, Bristol, BS2 8HW, United Kingdom (E-mail: Anthony.Morgan@ubht.nhs.uk).

J Thorac Cardiovasc Surg 2009;137:1021-2 $0022-5223 / \$ 36.00$

Copyright (C) 2009 by The American Association for Thoracic Surgery doi:10.1016/j.jtcvs.2008.03.019
}

tralateral recurrences despite adequate surgical treatment. In this family, no mutations in the FLCN gene were found.

\section{CLINICAL SUMMARY \\ Patient 1}

A 14-year-old girl presented with a small left-sided pneumothorax that was successfully treated with needle aspiration. She returned 2 months later with ipsilateral recurrence and underwent video-assisted thoracoscopic surgery. A left upper third pleurectomy and apicectomy were carried out. Two weeks later, a contralateral right-sided pneumothorax developed, and she underwent right video-assisted thoracoscopic surgery, apicectomy, and pleurectomy. A recurrence on the left side developed 9 months later. Computed tomography showed no pleural bulla or interstitial lung disease. Open thoracotomy revealed a complete regrowth of parietal pleura. A complete pleurectomy was carried out, and she remains well 6 years after the procedure.

\section{Patient 2}

The elder brother of patient 1 presented at 17 years of age with a small left pneumothorax that was treated with 